\title{
La Gavia: historia de la transformación de una hacienda
}

\author{
GuZmán Urbiola, Xavier (2003), La GaVia. Una hacienda en el \\ centro de la historia, Promotora la Gavia, México, 159 pp.
}

La Gavia. Una hacienda en el centro de la historia es el nombre del libro de Xavier Guzmán que se dio a conocer en el invierno de 2003. Está organizado en tres capítulos a los cuales tituló: La descripción cronológica tradicional; la producción, los intereses, el dinero y los mercados, 1799-1933 y Del mundo de la Gavia y de la Gavia al mundo, más las conclusiones. Lleva un prólogo de Josefina Zoraida Vázquez del Centro de Estudios Históricos de El Colegio de México, quien resalta la importancia de los estudios de caso en la microhistoria de México, y la pluma ágil y agradable prosa de Xavier Guzmán. Todo esto nos motiva a los historiadores regionales para seguir en nuestro quehacer histórico de búsqueda de datos y documentos que permitan percibir los cambios que nos llevan a contextos históricos nacionales e internacionales en el devenir de la historia, y particularmente, como afirma J.Z. Vázquez, el importante fenómeno de la transformación de las haciendas, una institución importante en la vida mexicana.

El primer capítulo lo subdivide en dos apartados: el primero habla de los pueblos indígenas, como constructores materiales del lugar y el segundo relata la formación de la hacienda, sus propietarios y constructores físicos. Cabe destacar las descripciones que el autor hace de los matlatzincas, a los que califica como pueblo principal de la zona; a los mazahuas que se sabe tan poco de ellos y a los otomíes que fueron los más numerosos, lo que da por resultado la multietnicidad del valle de Toluca. Esta diversidad cultural aún se percibe en la zona geográfica de la hacienda de La Gavia, y trae aparejado patrones de conducta, modos de vida y tradiciones afines y distintas a la vez.

En la segunda parte, el autor aclara que el nombre verdadero de la hacienda es 'Nuestra Señora de la Candelaria', y fue hasta 1663 cuando se acuñó el nombre de 'La Gavia' por José Sámano, quien nunca poseyó la hacienda, pero la bautizó con este nombre cuando vieron un plano de la propiedad y se comentó que el contorno tenía la forma de la vela mayor de los navíos, llamada precisamente gavia (p. 40). La historia de este lugar se inicia en 
1539, al recibir el encomendero Alonso de Ávila una merced para ganado mayor "en los términos del pueblo de Tlalchichipa" (p. 31), entre los poblados actuales de Toluca, Zinacantepec y Almoloya de Juárez. Merced que en 1549 cambió un par de 'encomiendas' en Chilchota, Valladolid y en Tonalá Juan de Sámano Medinilla con Alonso de Ávila. Este intercambio fue hecho fuera de la ley: recordemos aquello de "obedézcase pero no se cumpla”. El hecho fue que una de las familias más representativas del valle de Toluca, los Sámano, conservaron y ampliaron la hacienda hasta inicios del siglo XVIII, a través de matrimonios ventajosos como fue el Juan de Sámano Castrejón con Beatriz de Turcios, quien aportó el rancho de Turcios, posteriormente se incorporó el rancho de Arbayo, las haciendas de San Pedro, Soyacantla, la Cercada, Tejalpa, Acatitlán y la Huerta, así como los pueblos de Amanalco, el Rincón, San Mateo, San Bartolo, San Francisco y las llamadas "tierras de La Peña". Así se formó un gran latifundio que comprendió 1,500 caballerías, o sea casi 65 mil hectáreas.

La propiedad fue pasando de un dueño a otro: en 1708 la viuda de Carlos de Sámano Salamanca, Benita Cesatti del Castello, "la puso en pregón" o sea la anunció para su venta, y el comprador fue Pedro Ximénez de los Cobos, un hombre influyente de la ciudad de México, quien únicamente la poseyó por nueve años. Aquel fue un tiempo difícil, sobre todo porque los pueblos campesinos de Temascaltepec y Texcaltitlán interpusieron derechos de propiedad, por falta de definición de los linderos. Otro litigio importante fue el que sostuvo con la Compañía de Jesús, quienes habían rentado al pueblo de Texcaltitlán un sitio llamado Atescapan y que pertenecía a La Gavia. El pleito se prolongó por años, así que el dueño decidió vender la hacienda en 1717 a los Jesuitas, quienes a su vez anexaron las tierras que poseían, formándose una propiedad descomunal que para fines del siglo XVIII comprendió casi 136 mil hectáreas.

Así La Gavia fue dueña de la mitad del poniente del Nevado de Toluca: incluía Suchitepec, Villa Victoria, Valle de Bravo, Temascaltepec, Texcaltitlán, Sultepec, Tenancingo, Tenango y, dando la vuelta, bordeaba Zinacantepec y Almolya de Juárez (pág. 43). Fue un lugar muy productivo que en 1767 se vino abajo al ser expulsados los Jesuitas de la Nueva España y pasar la propiedad a la llamada Junta de Temporalidades, quien administró los bienes de la Compañía.

En 1777 Pedro Romero de Terreros, primer conde de Regla, adquirió varios bienes, entre ellos La Gavia. A la muerte del due- 
ño se le asignó al mayorazgo de su tercer hijo, José María Antonio de Terreros Trebuesto y Dávalos, marqués de San Cristóbal, persona que nunca pisó la tierra y no dejó descendencia, pasando a poder de su sobrino, Pedro José Romero de Terreros y Rodríguez de Pedroso, tercer conde de Regla, a quien le tocó vivir la Guerra de Independencia y ver cómo era invadida su propiedad por ambos ejércitos. En 1837 hipotecó La Gavia a la casa Viuda de Echeverría e Hijos, que se encontraba en Veracruz y la perdió.

La hacienda pasó a manos de una empresa con diversos socios, pero en realidad siempre estuvo en manos de los descendientes de María Francisca Mignoni viuda de Echeverría, figura principal de la casa comercial, así que la heredó a los descendientes de su hija mayor, Guadalupe Echeverri Mignoni y Jacinto Riba. Esta familia la mantuvo en su poder por 113 años, vendiéndola en 1950. Al frente de La Gavia aparecen los nombres de Francisco Xavier Echeverri Mignoni, hijo de María Francisca, posteriormente sus nietos Pedro Gorozpe, Antonio Riba Echeverría, y por último ostentaron la propiedad a principios del siglo Xx Antonio Riba Cervantes y su esposa Dolores García Pimentel y Elguero (pág. 49). Personajes importantes del siglo XIX fueron: Francisco Xavier Echeverría, quien fue dos veces secretario de Hacienda y encargado del despacho del Poder Ejecutivo a la caída de Anastasio Bustamante, a quien se le apodó El Presidente; Pedro Gorozpe, marido de Guadalupe Morán, Marquesa de Vivanco, que fue dama de la corte de Maximiliano; Antonio Riba Echeverri fue diputado federal y amigo de Porfirio Díaz, fungió además como presidente del consejo de administración del Banco del Estado de México, s.A.

En La Gavia se reflejan los ires y venires de la historia de México; por ejemplo durante el porfiriato se ven los aires de la modernidad, con una estación de ferrocarril a sólo 20 kilómetros del casco, lo que permite el intercambio de los productos comerciales; se construye una escuela para los hijos de los trabajadores. Don Antonio Riba Cervantes poseyó autos, motocicletas y hasta aviones. Entre 1912 y 1918 estuvo parcialmente invadida por los zapatistas y sufrió un incendio. A la vez que Genovevo de la O, Francisco Pacheco y Ángel Barrios hicieron buenos negocios con la hacienda, se cuenta que hubo muchas crueldades, se quemaron pueblos como escarmiento y se expusieron cadáveres.

Asimismo, dos pueblos, San Andrés de los Gama y Santiago Texcaltitlán, solicitaron ejidos al gobernador de entonces Gusta- 
vo Baz en 1915, y fue hasta 1929 cuado se realizó el desmembramiento de La Gavia por primera vez.

Vendrá después el presidente Lázaro Cárdenas a poner orden entre colonos y ejidatarios en 1936 y le tocará al presidente Miguel Alemán concluir los repartos y firmar las dotaciones últimas y definitivas en 1950. Se dejaron 220 hectáreas en inafectabilidad para el casco de la hacienda. Es decir, sólo quedó 1.6\% del territorio original.

Con todos estos acontecimientos, la propietaria de La Gavia, Dolores García Pimentel, optó por vender la propiedad a José Ramón Albarrán Pliego, un exitoso hombre de negocios del ramo de la fundición, quien la poseyó hasta su muerte en 1981. Remodeló el casco de la hacienda, adaptó la casa, diseñó muchos de sus paisajes y la embelleció. Xavier Guzmán atinadamente lo califica de hombre trabajador, emprendedor y tozudo. Quienes tuvimos el privilegio de conocerlo en su hacienda, sentimos mucho el que Xavier no lo hubiera tratado, pues supongo que él hubiera sido el cronista contratado por don José Ramón para elaborar la primera historia de La Gavia. Pero con la publicación de este libro la deuda queda saldada. Cierra este primer capítulo con leyendas, tradiciones y decires de la hacienda por demás interesantes y amenos.

El segundo capítulo analiza la producción de La Gavia entre 1799 y 1933. El autor tuvo la inmensa suerte de encontrar todos los libros de registros de contabilidad en estos años. Asegura que la hacienda dependió básicamente de ocho productos para mantenerse: ganado vacuno, caballar y mular; trigo, producto que se vendía íntegro al molino La Unión, propiedad de la familia Henkel; madera en tablones, leña, ocote y carbón; sus pastos y el arrendamiento de tierras. Pero la principal actividad y sustento real fue el ganado de zerda.

Los lugares con los que comerciaba fueron Toluca y las minas al sur del valle de Toluca. Otra actividad que anexa fue la de ser casa prestamista y en escala mínima cobra el agua de los ríos que la cruzaban a la Compañía Minera del Rincón. Entre 1885 y 1891 se agrega un producto importantísimo que fue el zacatón, vendido a Europa y apreciado por los establos del ejército alemán. Como buena hacienda del centro produjo pulque, aunque cabe aclarar que nunca se caracterizó por ser una hacienda pulquera, pero sí abasteció al consumo del lugar y pueblos aledaños.

Cabe mencionar que en los últimos años dejó de ser importante el zacatón y el trigo, cambiándose al cultivo de la cebada, que 
se vendía a la compañía Cervecera de Toluca y México, S.A; a su vez, el maíz y los productos del aserradero desplazarón al trigo. También existió un rubro regular de ingreso: el cobro por concepto de derechos de paso por caminos que cruzaban la hacienda (pág. 71).

El tercer capítulo, titulado Del mundo a La Gavia y de la Gavia al mundo, es muy sugestivo, en virtud de que está lleno de relatos, anécdotas y curiosidades. Al notar la influencia de los acontecimientos internacionales, nacionales y regionales, Xavier Guzmán acertadamente se pregunta: ¿Para qué eran entonces aptas estas regiones? ¿Qué necesidades podían cubrirse con lo que ahí se produjera? ¿Dónde vender lo que se obtuviera de la tierra? O al valorar la producción del zacatón y su exportación, ¿̇por qué no fabricar un cepillo o una escoba en México y exportar el producto con un mayor valor agregado? Las respuestas así son obvias, encontrando que los negocios agrícolas de gran envergadura sólo llegaron hasta el siglo XIX. Y muchos de estos productos se vincularon entre el mundo agrícola de La Gavia y la industria química teutona, como en el caso del zacatón, que utilizaban el extracto líquido de la raíz de este producto para fabricar explosivos, lo que resultaba más costeable transportar el líquido y no toda la planta. Otro tipo de cuestionamientos son los referentes a la singularidad regional de La Gavia con los acontecimientos nacionales, por ello se pregunta: ¿Quiénes eran los zapatistas que invadieron la hacienda entre 1912 y 1917 y no eran gente armada, sino agricultores que intentaron tener negocios con los de la hacienda? O cómo reaccionaron los dueños de La Gavia al saber que se quemó la casa grande por un mal entendido entre los revolucionarios. Entonces se cuestiona: ¿Qué es una revolución? Que por cierto no trastocó nada del lugar, ni afecto la economía de los dueños, quienes siguieron manteniendo su casa de Toluca, a la cual casi no iban y su gran residencia en la ciudad de México. Además sabemos que en esos mismos años de invasión a la hacienda, los Riba Cervantes y García Pimentel hicieron por lo menos dos viajes a Europa, y en 1918 tuvieron la paz deseada y se retomaron los proyectos suspendidos

Es muy interesante el análisis que hace el autor de este libro con respecto a la invasión zapatista: "La Gavia se encontraba invadida y su dueño se quejaba de su triste situación. Entonces se realizaron enormes ventas de trigo (para abastecer a las ciudades) y poco después de maíz, el cual nunca antes se había anotado. ¿Para los zapatistas, que no comían pan sino tortillas? ¿Para sus- 
tentar a los enemigos del dueño? De ser correcta esta apreciación, entonces encontramos, por un lado, a un Riba Cervantes que juega un doble papel, quejándose de las invasiones zapatistas y haciéndoles la guerra, pero a la vez sembrando, cosechando, vendiendo y beneficiándose de la invasión a su propiedad. Por otro lado, a un zapatismo terrible por sus métodos y consecuencias, pero también bonancible para el hacendado. Parece evidente que cuando gobernaron los enemigos de La Gavia, a ésta le fue bien. Para Riba Cervantes el zapatismo fue buen negocio, pero mala imagen" (pág. 146).

En las conclusiones, Xavier Guzmán plantea en su peculiar estilo la complementariedad entre la historia regional y la nacional, y nos asegura que la historia regional no sólo importa a los lugareños, sino que nos importa a todos, ya que desde lo anecdótico la historia crece, se humaniza y evidencia la complejidad de un caso singular que matiza a la historia nacional.

A manera de conclusión, podemos anotar que el libro es atractivo, no sólo por las hermosas fotografías que en él se encuentran, sino por la trama de la obra, por los personajes del pasado, que los recrea y revive en carne y hueso, logrando Xavier Guzmán establecer un diálogo ameno con ellos y retratándolos perfectamente. Pintando al campo y a las aldeas del lugar con todos sus dimes y diretes, mostrando una hacienda viva, llena de contrastes, en donde cada lugar se expresa y cuenta su propia historia, y no es únicamente una historia del agro mexiquense, ni de la colonia: es una historia global enlazada, en ocasiones, con el mundo y siempre con su entorno geográfico e histórico.

Un gran acierto en la lectura son los cuestionamientos que el autor se hace y los compara con nosotros, donde vemos su manera de escribir y entender la historia a nivel local y proyectarla más allá de sus límites físicos. Y como apunta magistralmente Josefina Zoraida Vázquez: “cumple con el viejo anhelo de detener el tiempo”.

María Teresa Jarquín Ortega El Colegio Mexiquense, A. C. tjarquin@cmq.edu.mx 